\title{
A Study on the Interpreting Self-Efficacy (ISE) Scale Drawing of Business English Majors at the Universities of Applied Sciences-A Case Study of a Certain University of Applied Sciences in Dalian
}

\author{
Liu Chen \\ Dept. of English, Foreign Languages School, Dalian Neusoft University of Information \\ Dalian, Liaoning
}

\begin{abstract}
The aim of this study is to draw and test the Interpreting Self- Efficacy (ISE) scale of Business English majors at the Universities of Applied Sciences to improve the academic achievement of the Interpreting course of Business English majors and to better promote the cultivation of Business English majors at the Universities of Applied Sciences. Through literature search, online questionnaire and expert interview, this paper sums up the questions of the ISE scale of Business English majors at a certain Universities of Applied Sciences in Dalian, completes the test of reliability and validity, and discusses and analyzes the problems appearing in the factor test. The study found that the self-efficacy of Business English majors at the Universities of Applied Sciences has a direct relation to students' learning habits and the perception of learning objectives.
\end{abstract}

Keywords-University of Applied Sciences; Business English Majors; ISE scale

\section{INTRODUCTION}

The concept of self-efficacy was first proposed by American educator, psychologist Bandura, who pointed out that self-efficacy is an individual's ability to accomplish a particular task, which has a strong influence on individual's willpower and choice of activities [1]. The combination of self-efficacy and English language learning appeared in the 21 st Century, which has only been studied for more than 10 years. The research topics at home and abroad include: the development of English self-efficacy scale, the research of English self-efficacy, the correlation between English self-efficacy and other learning factors, and the ways and methods of improving English self-efficacy [2]. Among them, the research objects of nearly half of the articles were selected as non-English majors, over $60 \%$ of the articles studied the general undergraduate students. Its characteristic has certain universality and representativeness, but still exposes insufficiency to other research object [3]. At present, there is a lack of research on the topic of English learning self-efficacy in the objects of Business English majors at Universities of Applied Sciences. At the same time, the study of self-efficacy of English language learning in China focuses on the multidimensional examination of oral, writing, listening and reading capability, lacking ISE drawing and analyzing. The research on the ISE for Business English majors at Universities of Applied Sciences is a blank.

Related research shows that self-efficacy and academic achievement have a close relationship [4]. Self-efficacy affects academic achievement directly or indirectly. The study of the relationship between self-efficacy, attribution, learning motivation and performance in the past has validated the direct impact of self-efficacy on academic achievement [5-6]. Therefore, in order to improve the academic achievement of the Interpreting course for Business English majors and better promote the cultivation of Business English majors at Universities of Applied Sciences, it is urgent to study the ISE for Business English majors at Universities of Applied Sciences.

\section{Preparation of the SCALE}

\section{A. Sample Pretest}

On March 2018, 78 students of Business English majors in the third year of a certain University of Applied Sciences in Dalian conducted a sample pretest, which aims to test whether the tested samples have distinction in their academic achievements, so as to ensure the measured samples of the ISE scale reflect the characteristics of the Business English junior in the University of Applied Sciences in Dalian, so as to make a further self-efficacy analysis of the samples.

Pretest volume consists of listening, language knowledge, cloze, reading comprehension and writing. Full marks are 100 points, and the test time would be 120 minutes. It is a proficiency test focusing on the students' comprehensive use of language and language skills. The structure of the test paper and the distribution of questions are in accordance with the Test for English majors Band 4 (TEM-4), the subjective and objective questions are of appropriate proportion in line with the requirements of the sample pretest. After the test, 78 students were then scored. The results are shown in Table I; In accordance with the TEM-4 identified criteria, lower than 60 points is identified as "Substandard", scores between $60-70$ as "Qualified", scores between 70-80 as "Good", higher than 80 points as "Excellent", the number for each dimension are shown in the following Figure I. 


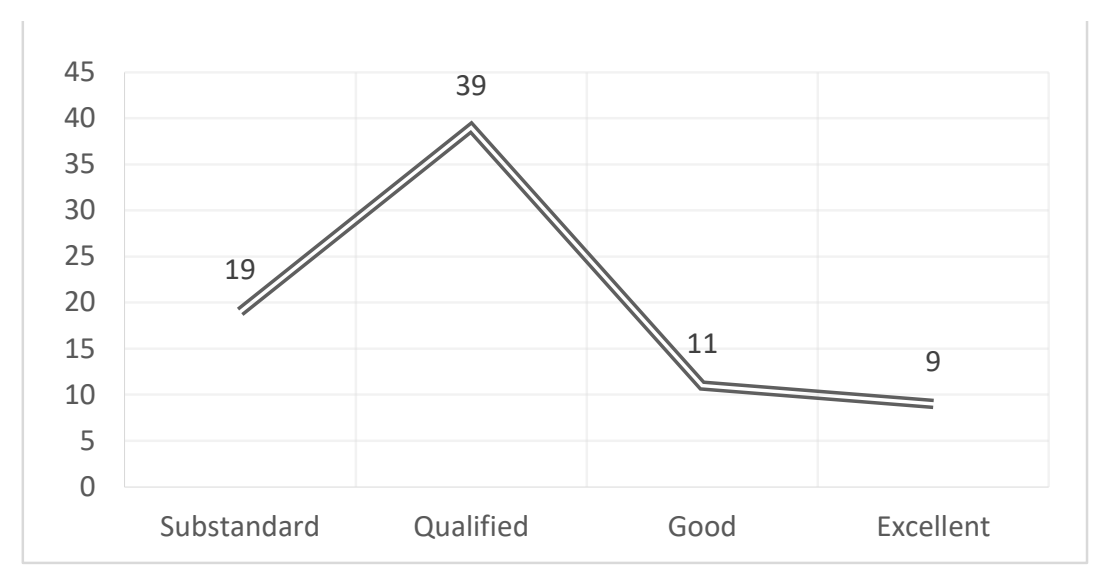

Fig. 1 Sample Pretest Score Distribution

TABLE I DESCRIPTIVE ANALYSIS OF SAMPLE PRETEST RESULTS

\begin{tabular}{|c|c|c|c|c|c|c|}
\hline Item & Sample Size & Minimum Value & Maximum Value & Average Value & Standard Deviation & Median \\
\hline Pretest scores & 78 & 32.0 & 89.0 & 63.8 & 12.3 & 64.5 \\
\hline
\end{tabular}

From the above, we know that the results of sample pretest are basically in accordance with normal distribution, meanwhile, it reflects the Business English majors at certain University of Applied Sciences in Dalian are not solid enough in English language learning and the polarization is more serious. Then, further analysis is approval.

\section{B. Theoretical Basis}

The research of self-efficacy should be followed by two basic principles- "Domain particularity" and "Domain Integrality".[1] While Schwarzer pointed out that the test of self-efficacy should embody the obstacle of accomplishing the task or the skill of accomplishing the task, so as to indicate that the completion of the task requires a certain degree of difficulty.[7] Interpreting teaching for undergraduates should be focused on consecutive Interpreting, its particularity and integrality, as well as the obstacle of accomplishing the task or the skill of accomplishing the task in setting questions, concentrate on the complexity in the output of Interpreting. According to Gile [8] who proposed the Effort Models for
Interpreting, Consecutive Interpreting can be divided into two phases: a listening comprehension-memory phase and the Interpreting output phase. In short, Consecutive Interpreting requires the translator to complete the input of information through the source language, analyze and memorize the information through the brain and notes, and then finish oral expression, which comprehensively reflects the translators' listening comprehension capability, information screening and processing capaability, memory capability and translation capability. At the same time, the translator is required to have good mental quality and adaptability.

In the question setting of the ISE for Business English majors at University of Applied Sciences, we should fully combine the features of Interpreting task, fully consider the obstacles to completion of Interpreting task. Its theoretical basis and corresponding question setting dimensions are shown in Table II:

TABLE II EFFORT MODELS FOR INTERPRETING AND CORRESPONDING ITEMS

\begin{tabular}{|c|l|l|}
\hline \multicolumn{2}{|c|}{ Theoretical Basis } & Corresponding Items \\
\hline \multirow{3}{*}{$\begin{array}{c}\text { Phase I: listening Comprehension } \\
\text { \& Memory }\end{array}$} & Listening comprehension & A sense of mastery of listening skills \\
\cline { 2 - 2 } & Note-taking assistance & Notes Assistant Skills Mastery \\
\cline { 2 - 2 } & Short-time Memory storage & A sense of aptitude for memory \\
\cline { 2 - 3 } & Information coordination & A sense of aptitude \\
\hline \multirow{3}{*}{$\begin{array}{c}\text { Phase II: Interpretating Output } \\
\end{array}$} & Memory & \multirow{2}{*}{ A sense of mastery of translation skills } \\
\cline { 2 - 3 } & Notes interpretation & \\
\cline { 2 - 3 } & Interpreting output &
\end{tabular}




\section{Preparation Steps}

According to Bandura's "Reciprocal Determinism"[9] and Morgan and Jinks' Morgan-Jinks Student Efficacy Scale,[10] through the network questionnaire survey, which covered the description of students' performance in learning Interpreting with self-confidence, and through interviews with three experts who are specialized in Interpreting teaching and research, we finally concludes and sums up the questions of the ISE scale for Business English majors at University of Applied Sciences, as shown in the Table III:

TABLE III THE QUESTIONS OF THE ISE FOR BUSINESS ENGLISH MAJORS AT UNIVERSITY OF APPLIED SCIENCES

\begin{tabular}{|l|l|}
\hline The sense of aptitude for Interpreting & Q1,Q9, Q \\
\hline The sense of Interpreting environment & Q2,Q11, \\
\hline The sense of completion of Interpreting tasks & Q3 \\
\hline $\begin{array}{l}\text { The sense of achievement on Interpreting learning } \\
\text { objectives }\end{array}$ & Q12 \\
\hline The sense of mastery on Interpreting skills & Q4,Q5,Q \\
& $13, \mathrm{Q} 14$ \\
\hline The sense of effort in Interpreting learning & Q6,Q7,Q \\
& 15 \\
\hline The sense of behavior control in Interpreting learning & Q8,Q16 \\
\end{tabular}

The scale has followed the following characteristics in the design of the question: (1) The subject is "Me", the aim is to measure the subjective beliefs of the individual; (2) The expression of the question contains verbs such as "can" and "will", indicating that the completion of the task is derived from the individual's capability, and (3) the task includes obstacles requiring certain skills, which is designed to ensure the self-efficacy is assessed in a difficult activity.

The scale is given by the teacher and collected on the spot after students finishing all the questions, which aimed to ensure the validity of the measure and the reliability of the data. Scale test will last for 10 minutes, before the release of the scale, the instructor is required to do detailed instructions of how to answer these questions. The 5-point scale method is used to measure the question, from "completely disagree" to "totally agree", as 1 point to 5 points respectively. The actual release amount is 78, with 78 valid scale withdrew, the effective rate of the scale reaches $100 \%$. We will type the raw data into SPSS 19.0 to examine the reliability and validity of the scale.

\section{SCALE TEST}

\section{A. Reliability Test}

Data are entered into SPSS 19.0 for reliability test. The value of reliability coefficient is 0.840 , and the value of Cronbach's Alpha of Q2, Q11, Q6 and Q15 is 0.843, 0.863, and 0.868 , which is higher than the $\operatorname{Alpha}(\alpha)$ Coefficient value, 0.840 , and the CITC Value of these 4 analysis items is lower than 0.3 , which is $0.260,-0.130$ and -0.246 respectively, we consider that these 4 items should be deleted; the analysis is done again after the 4 items are deleted, the value of Cronbach's Alpha of Q1, Q17 is 0.906 and 0.904 respectively, which is higher than the reliability coefficient value, 0.902 , we consider that these 2 items should be deleted. After the items are deleted, the reliability coefficient value is 0.909 , it is higher than 0.9 , which shows that the reliability of the data is very high. And the CITC value of all the corresponding items is higher than 0.5 , which shows a good correlation between the analysis items, and the reliability of the data is good.

\section{B. Structural Validity Test}

In order to check the structure validity of the scale, we analyzed the scale data by exploratory factor analysis. Through the principal component analysis, we obtain the value of KMO, 0.902 , is higher than 0.6 , that means the data has validity and satisfies the prerequisite of factor analysis, and the data can be used for factor analysis research. Data pass the Bartlett Spherical degree test $(\mathrm{P}<0.05)$ indicates that the research data are suitable for factor analysis. Factor analysis altogether extracts 3 factors, the number of factors are consistent with the expected. All the feature root values are higher than 1 . The variance interpretation rate after the rotation of these three factors are $29.247 \%, 27.64 \%$ and $12.991 \%$ respectively, the interpretation rate of cumulative variance after rotation is $69.878 \%$. The maximum variance rotation method is used to rotate, and the common degree values of all the research items are higher than 0.4 which indicates a strong correlation between the research items and the factors, and the factors can effectively extract the information. Factors for the information extraction of the research items, as well as the corresponding relationship between the factors and the research items, see Table IV. 


\begin{tabular}{|c|c|c|c|c|}
\hline \multirow[t]{2}{*}{ Question } & \multicolumn{3}{|c|}{ Factor Loading Coefficient } & \multirow[t]{2}{*}{ Communalities } \\
\hline & Factor 1 & Factor 2 & Factor 3 & \\
\hline $\begin{array}{l}\text { Q7 I will carefully analyze the reasons for the problems encountered in } \\
\text { Interpreting, and find a way to solve them. }\end{array}$ & 0.828 & & & 0.807 \\
\hline $\begin{array}{l}\text { Q8 I will not be impatient, and timely calm myself down when I find it's } \\
\text { difficult to interpret. }\end{array}$ & 0.618 & & & 0.706 \\
\hline Q9 I think I have a good mental quality and adaptability. & 0.685 & & & 0.564 \\
\hline Q10 I think I have a gift for English Interpreting. & 0.653 & & & 0.694 \\
\hline Q16 I can always concentrate on finishing an Interpreting. & 0.782 & & & 0.700 \\
\hline Q3 I believe I can finish an English Interpreting. & & 0.666 & & 0.636 \\
\hline $\begin{array}{l}\text { Q4 I am confident that I can use the relevant background knowledge to } \\
\text { help me finish an Interpreting. }\end{array}$ & & 0.728 & & 0.670 \\
\hline $\begin{array}{l}\text { Q5 I am confident that I can better use all kinds of knowledge to grasp he } \\
\text { meaning of the listening material and complete the language input. }\end{array}$ & & 0.539 & & 0.653 \\
\hline $\begin{array}{l}\text { Q13 I am confident that I can complete the Interpreting task with the help } \\
\text { of translation knowledge. }\end{array}$ & & 0.704 & & 0.719 \\
\hline $\begin{array}{l}\text { Q14 I'm confident that I can use my notes to help me finish the Interpreting } \\
\text { task. }\end{array}$ & & 0.793 & & 0.666 \\
\hline Q12 I believe I can improve my Interpreting by working hard. & & & 0.867 & 0.872 \\
\hline
\end{tabular}

Factor 1 contains Q7, Q8, Q9, Q10 and Q16 involved in three dimensions of items- "The sense of effort in Interpreting learning ", "The sense of behavior control in Interpreting learning" and "The sense of aptitude for Interpreting". Q3 is corresponding to "The sense of completion of Interpreting task ", Q4, Q5, Q13 and Q14 are corresponding to the "The sense of mastery on Interpreting skills", these two make up the second factor; "The sense of achievement on Interpreting learning objectives" is corresponding to Q12 which makes up the third factor as a single dimension.

\section{DISCUSSION AND ANALYSIS}

"The sense of effort in Interpreting learning" and "The sense of behavior control in Interpreting learning" in factor 1 are the adjustment and monitoring of learners' learning behavior and cognitive activities, which belong to the capability of Interpreting metacognition; and "The sense of aptitude for Interpreting" is the subjective judgment of learners' capability to interpret, these two constitute the factor 1. At the same time, "The sense of completion of Interpreting task" corresponding to Q3 and "The sense of mastery on Interpreting skills" corresponding to Q4, Q5, Q13 and Q14 arise the similar problem, the former belongs to the cognitive capability of Interpreting, the latter is the capability of Interpreting metacognition. "The sense of achievement on Interpreting learning objectives" constitutes the third factor alone other than accompanying with "The sense of aptitude for Interpreting" and "The sense of completion of Interpreting task", these three problems are worth discussing.
First of all, "The sense of effort in Interpreting learning" , "The sense of behavior control in Interpreting learning" and "The sense of aptitude for Interpreting" constitute a factor indicates that students tend to make a connection with the capability of behavior control and talent, lacking objective understanding of efforts and behavioral control, subjectively think that working hard and control of their learning behavior are a kind of natural talent, which indirectly proved that the learners' subjective initiative in Interpreting is poor; Secondly, "The sense of mastery on Interpreting skills" and "The sense of completion of Interpreting task" are classified as the same factor, which indicates that students' Interpreting learning relies on the adjustment of cognitive activities, that is, students are more inclined to complete Interpreting study by mastering Interpreting skills, lacking willingness to enhance cognitive capability through self-efficacy; Finally, "The sense of completion of Interpreting task" and "The sense of achievement on Interpreting learning objectives" are not classified as the same factor, which embodies misunderstanding of the Interpreting learning objectives among students: On the one hand, Interpreting is a comprehensive skill, the improvement of listening comprehension, translation skills cannot be regarded as the improvement of Interpreting capability. The misunderstanding of learning objectives will inevitably result in the inconsistency between "The sense of completion of Interpreting task" and "The sense of achievement on Interpreting learning objectives"; On the other hand, it also reflects the insufficiency and incompleteness of the question in the dimension of "The sense of achievement on Interpreting learning objectives", the way of description of the question still needs to be improved, and the question still needs to be added. 


\section{CONCLUSION}

The drawing of ISE scale for Business English majors at University of Applied Sciences is of great significance for further research on the learning motivation, learning strategies and academic achievement. This study found that self-efficacy of students majoring in Business English at University of Applied Sciences has a direct connection to students' learning habits and the perception of learning objectives. The deficiency of the research is that the ISE scale is insufficient in setting questions in certain dimension, and the way of question description needs to be polished, the question still needs to be supplemented and revised appropriately.

\section{REFERENCES}

[1] Bandura A. Self-efficacy: The Exercise of Control [M]. New York: Freeman, 1997: 52-112.

[2] Wang Xuesong, Yang Yang. The Drawing and Multidimensional Examination of English Reading Self-Efficacy Scale for Non-English Majors [J]. Journal of Hebei University of Economics and Trade (Comprehensive Edition), 2013 (3): 102. (In Chinese)

[3] Meng Bin, Chen Ting. Study on Self-Efficacy Scale of English Learning in China [J]. Journal of Jiangxi Institute of Education (Social Sciences), 2011(2): 93. (In Chinese)
[4] Zhang Risheng, Yuan Limin. Study on the Relationship between Foreign Language Anxiety, Self-Efficacy and Foreign Language Performance in College Students[J].Psychological Development and Education, 2004 (3): 56-61.(In Chinese)

[5] Wang Kairong, Sin Tao, Li Qiong. Study on the Relationship between Self-efficacy, Attribution and Academic Performance of Middle School Students [J]. Psychological Development and Education, 1999 (4): 22-25.(In Chinese)

[6] Zuo Bin, Tan Yali. Relationship between Academic Self-Efficacy, Learning Motivation and Academic Achievement in Junior Middle School Students [J]. Applied Psychology,2002 (4): 24-27,46.(In Chinese)

[7] Schwarzer R, Mueller J, Greenglass E. Assessment of General Perceived Self-Efficacy on the Internet: Data Collection in Cyberspace [J]. Anxiety, Stress and Copying, 1993(3): 145-161.

[8] Gile D. 1995. Basic Concepts and Models for Interpreter and Translator Training, John Benjamins Publishing Company.

[9] Yang Xinyu. The Educational Significance of Bandura Reciprocal Determinism [J]. Journal of Xinxiang Teachers College, 2006 (5): 92-93.(In Chinese)

[10] Jinks J, Morgan V.Children's Percieved Academic Self-Efficacy: an Inventory Scale $[\mathrm{J}]$. Educational Strategies, Issue and Ideaas, 1999(4):224-230 